Int. Agrophys., 2021, 35, 251-256

INTERNATIONAL

\title{
Thermal properties of wood and wood composites made from wood waste**
}

\author{
Monika Božiková@*, Petr Kotoulek, Matúš Bilčík@, Lubomír Kubik@, Zuzana Hlaváčová@, \\ and Peter Hlaváč
}

Department of Physics, Slovak University of Agriculture in Nitra, Tr. A. Hlinku 2, SK-949 76 Nitra, Slovakia

Received June 26, 2021; accepted September 21, 2021

\begin{abstract}
Thermal characteristics represented by thermal parameters are very important for wood and wood-based products. They are influenced by internal and external factors such as: structure, temperature, moisture content, etc. Based on these factors the main aim of this article is the presentation of thermal conductivity, thermal diffusivity, and volume specific heat for five selected samples of wood with different moisture contents and wood fibre orientation. The next materials to be assessed were oriented strand boards made from the identical wood types. The wood samples had a tangential and radial orientation of fibres. Thermal conductivity and thermal diffusivity were examined through the use of a dynamic plane source method convenient for materials with the low thermal conductivity. The volume specific heat was calculated from definition equation. The moisture content was measured through the use of the gravimetric method and moisture analyser MAC 210/WH. The experimentally obtained relationships between thermal conductivity, thermal diffusivity and relative moisture content have resulted in increasing progress and in turn, the relationship of volume specific heat to the moisture content can be described by a polynomial function. The final relationships were mathematically described by regression equations and coefficients of determination. In both theoretical and practical contexts, the beneficial results for the thermal parameters of wood composites are made for different types of wood waste made in Slovakia, the thermophysical parameters of which were analysed and compared.

Keywords: thermal conductivity, thermal diffusivity, volume specific heat, orientation, moisture content
\end{abstract}

*Corresponding author e-mail: Monika.Bozikova@uniag.sk

**The research was supported by the Operational Programme Integrated Infrastructure within the project: Demand-driven research for the sustainable and innovative food, Drive4SIFood 313011V336, cofinanced by the European Regional Development Fund (2019-2023).

\section{INTRODUCTION}

During the processing of wood for wood-based products mechanical and thermal stresses often occur. The temperature changes affect the level of wood moisture because heat transport cannot be separated from water transport. The mechanism of conduction is the dominant process of heat transfer through wood and wood-based products, but convection and radiation are also included, mainly in the form of boundary conditions. Heat conduction takes place when a temperature gradient exists in a solid medium. It may be described by Fourier's Law (Gustafsson, 1991; Sobota, 2014), where $\lambda$ is the thermal conductivity $\left(\mathrm{W} \mathrm{m}^{-1} \mathrm{~K}^{-1}\right)$. The conduction of heat involves the transfer of energy within a material without any motion of the material as a whole. The velocity of the temperature equalization in a material during non-stationary processes characterizes thermal diffusivity $a\left(\mathrm{~m}^{2} \mathrm{~s}^{-1}\right)$ which has been defined in the literature (Suleiman et al., 1999; Adl-Zarrabi, 2004). The volume specific heat $c \rho\left(\mathrm{J} \mathrm{m}^{-3} \mathrm{~K}^{-1}\right)$ may be expressed as ratio thermal conductivity $\lambda$ and thermal diffusivity $a$ (Bouguerra et al., 2001; Nakaya et al., 2016). The thermal parameters of wood and wood-based products are affected by many internal and external factors such as: moisture content (Troppova et al., 2014; Glass and Zelinka, 2010), temperature (Zhou et al., 2013), density of the wood, direction of heat flow with respect to the grain (Ružiak et al., 2017; Öner et al.,

(C) 2021 Institute of Agrophysics, Polish Academy of Sciences 
2009). The thermal properties of wood-based materials are required in applications such as fuel conversion, building construction and other fields of industry (Zi-Tao et al., 2011). The problem of thermal parameter measurements of wood-based panels has already been discussed in a previous study and new results of the property have been delivered by Sonderegger and Niemz (2012), Li et al. (2013). Steadystate methods are used for the detection of wood thermal parameters (Hrčka and Kurjatko, 2006). Transient methods were introduced by Adl-Zarrabi and Boström (2004), Tavman (1996). Avramidis and Lau (1992) which measured the thermal coefficients of wood particles using a transient heat-flow method. The TPS technique is described in detail by Gustafsson (1991) and Wechsler (1992). According Karawacki et al. (1992) the extended dynamic plane source (EDPS) method is convenient for low thermal conductivity materials (Beck and Arnold, 2003; Malinarič, 2004). It was applied to the detection of the thermophysical properties of the solid wood of coniferous trees by authors Krišták et al. (2019). Knowledge of the thermal properties of wood is essential for determining of its future usage. Based on the presented facts, the main aim of this research was the identification of the selected thermal properties for different types of woods and wood composites made from wood waste in Slovakia using the dynamic plane source (DPS) method. The main benefit of the research were to establish the relationships between the thermal parameters for the different moisture contents of wood and wood composites - oriented strand board (OSB) detected in the tangential and radial direction.

\section{MATERIALS AND METHODS}

The thermal conductivity, thermal diffusivity and the volume specific heat of the wood and the products made in Slovakia were investigated. Measurements were performed on five types of wood samples: softwood - spruce (Picea abies) and black pine (Pinus nigra), hardwood - beech (Fagus silvatic) and oak (Quercus robur) and also on medium hardwood - chestnut (Aesculus hippocastanum). The relative moisture contents of the measured wood samples fell within the following range $-0-35 \%$. The wood samples were prepared in two directions. The tangential direction is perpendicular to the grain but tangent to the growth rings and the radial direction is normal to the growth rings and perpendicular to the grain in the radial direction. For every wood type special OSB samples were taken with tangential and radial directions. For the purpose of taking OSB thermal parameter measurements, samples from of wood-waste were prepared with the majority content of the wood species having a moisture content in the range $22-26 \%$ and the final product - samples of the examined OSB had a relative moisture content ranging from 4 to $7 \%$. The dimensions of all of the measured samples were the same $(150 \times 150 \mathrm{~mm})$ and with a thickness of $15 \mathrm{~mm}$. Experimental identification of the thermal parameters was performed under laboratory conditions with an air temperature of $20^{\circ} \mathrm{C}$, an atmospheric pressure of $101.3 \mathrm{kPa}$ and a relative air humidity of $42.5 \%$. The relative moisture content $\omega_{\text {rel }}$ of the measured samples was calculated as the ratio of the water mass to the mass of the dry sample multiplied by 100\% (Glass and Zelinka, 2010). The gravimetric method was used to determine the moisture content. The mass of the wood samples was measured during the drying process using analytical laboratory scales Kern ADB (Kern, Germany) with an accuracy of $0.0001 \mathrm{~g}$. A laboratory oven SLW 32 STD (Intertec Ltd., Germany) with an accuracy of $0.1^{\circ} \mathrm{C}$ was used for sample drying. The samples were dried with air that had a temperature of $103 \pm 2^{\circ} \mathrm{C}$. A moisture analyser, MAC 210/WH (Radwag LLC, USA) was also used to compare the detected results. The thermal parameters were measured using thermal analyser Isomet 2104 (Applied Precision Ltd., Slovakia) and a surface probe with a measuring range of $0.04-0.3 \mathrm{~W} \mathrm{~m}^{-1} \mathrm{~K}^{-1}$. The measurement procedure is based on the DPS method described by Malinarič and Dieška (2009). A mathematical description was presented in detail by Wakeham et al. (1991) and Liang (1995).

\section{RESULTS AND DISCUSSION}

In the first series of measurements the values of thermal conductivity, thermal diffusivity and volume specific heat in the tangential direction were determined. In the second series, the same samples were examined in the radial direction. Each point in the graphical dependencies shown in Figs 1-4 represents the arithmetic average from twenty measurements. All of the experimental results were statistically processed. The calculated relative probable errors were in the range of $0.115-0.365 \%$. Based on the regression analysis results, the regression equations describing the relationship between the measured thermophysical parameters and the relative moisture content were identified. Thermal conductivity as a function of relative moisture content for samples of softwood, medium hardwood, and hardwood with tangential and radial direction of wood fibres can generally be described by the linear function of Eq. (1) with regression coefficients being presented in Table 1 .

$$
\lambda=A+B \omega_{r e l} .
$$

The thermal conductivity of wood samples with a moisture content ranging from 0 to $35 \%$ with a tangential orientation of the wood fibres (Fig. 1) was in the range $0.062-0.091 \mathrm{~W} \mathrm{~m}^{-1} \mathrm{~K}^{-1}$ for softwood - spruce and for samples of black pine it was in the range $0.074-0.105 \mathrm{~W} \mathrm{~m}^{-1} \mathrm{~K}^{-1}$. The hardwood samples had thermal conductivity values in the following range: beech $0.103-0.139 \mathrm{~W} \mathrm{~m}^{-1} \mathrm{~K}^{-1}$ and oak 0.118-0.154 $\mathrm{W} \mathrm{m}^{-1} \mathrm{~K}^{-1}$, for the medium hardwood sample - chestnut was characterized by values ranging from 0.087 to $0.120 \mathrm{~W} \mathrm{~m}^{-1} \mathrm{~K}^{-1}$. Furthermore, as a part of the numerical evaluation of the results, there was a focus on determining the difference in the thermal conductivity values in the tangential direction for hardwood and medium hardwood samples, 
which was on average more than $37.2 \%$ (the reference sample was chestnut). In the case of the softwood samples (spruce and pine), an average difference $32.5 \%$ between the values of thermal conductivity in the tangential direction was found. The values of thermal conductivity in the radial direction (Fig. 2) are higher than the values in the tangential direction. Values of $\lambda$ were highest for hardwood - beech (0.118-0.158 $\left.\mathrm{W} \mathrm{m}^{-1} \mathrm{~K}^{-1}\right)$ and oak $\left(0.134-0.174 \mathrm{~W} \mathrm{~m}^{-1} \mathrm{~K}^{-1}\right)$. The lowest thermal conductivity values were recorded for the softwood samples - spruce $\left(0.072-0.097 \mathrm{~W} \mathrm{~m}^{-1} \mathrm{~K}^{-1}\right)$ and black pine $\left(0.085-0.116 \mathrm{~W} \mathrm{~m}^{-1} \mathrm{~K}^{-1}\right)$. When the values of thermal conductivity for wood samples in the radial direction are compared, the hardwood has an average thermal conductivity which is $33.3 \%$ higher than the medium hardwood and the softwood produced a value which is $31.8 \%$ lower than the reference sample of medium hardwood (chestnut).

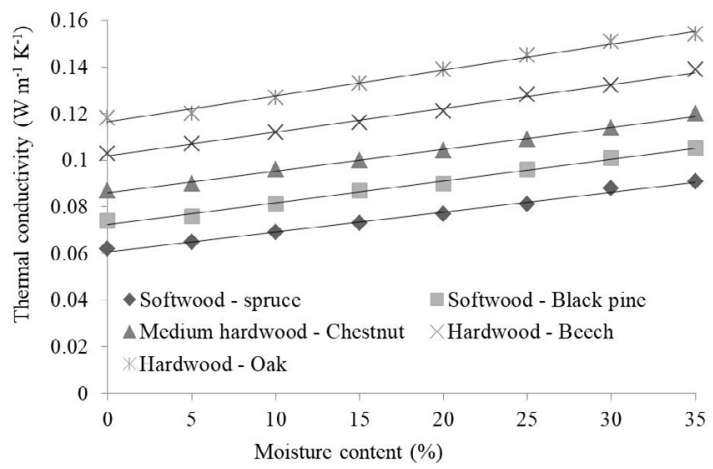

Fig. 1. Dependences of wood thermal conductivity on the moisture content in the tangential direction.

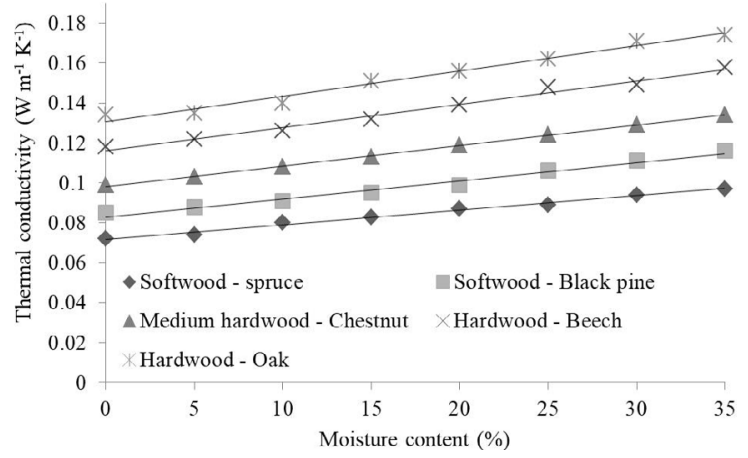

Fig. 2. Dependences of wood thermal conductivity on the moisture content in the radial direction.

Another investigated thermal parameter was thermal diffusivity, the measurement results are shown in Fig. 3. Experimental dependences had a nonlinear shape, thermal diffusivity increases with increasing water content which may be mathematically described by a polynomial function of the second degree - Eq. (2).

$$
a=C \omega_{r e l}^{2}+D \omega_{r e l}+E .
$$

The coefficients of the regression equation $\mathrm{C}, \mathrm{D}$ and $\mathrm{E}$ and the coefficients of determination $\mathrm{R}^{2}$ for the dependence $a=\mathrm{f}\left(\omega_{\text {rel }}\right)$ had the values given in Table 2 . The thermal diffusivity for the tangential orientation of wood fibres with a relative moisture content in the range of $0-35 \%$ was $0.127-0.177 \mathrm{~mm}^{2} \mathrm{~s}^{-1}$ for soft wood, while hardwood samples had a thermal diffusivity of $0.140-0.195 \mathrm{~mm}^{2} \mathrm{~s}^{-1}$. The average difference between the thermal diffusivity in the tangential and radial directions was $1.98 \%$ for hardwood and it ranged from 1.88 to $2.05 \%$ for the softwood samples.

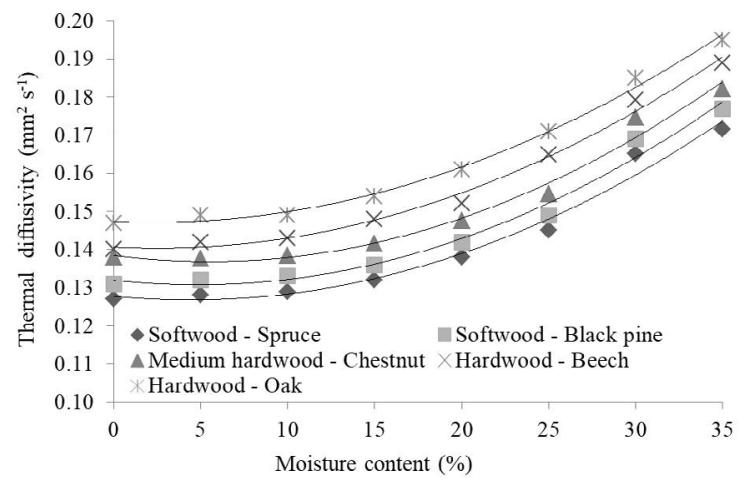

Fig. 3. Dependences of wood thermal diffusivity on the moisture content in the tangential direction.

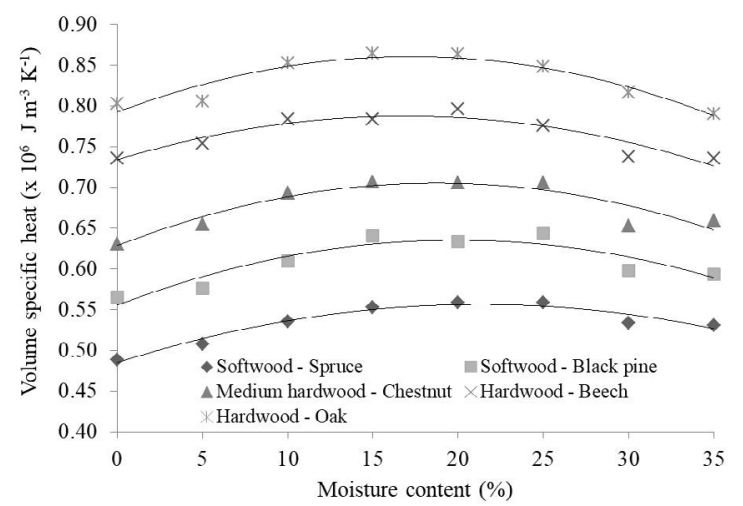

Fig. 4. Dependences of the volume specific heat on the moisture content in the tangential direction.

Table 1. Results of regression analyses for thermal conductivity relationships

\begin{tabular}{lccccccc}
\hline $\begin{array}{l}\text { Coefficients } \\
\text { of regression } \\
\text { equation (1) }\end{array}$ & $\begin{array}{c}\mathrm{A} \\
\left(\mathrm{W} \mathrm{m}^{-1} \mathrm{~K}^{-1}\right)(\%)^{-1}\end{array}$ & \multicolumn{2}{c}{$\begin{array}{c}\mathrm{B} \\
\left(\mathrm{W} \mathrm{m}^{-1} \mathrm{~K}^{-1}\right)\end{array}$} & & \multicolumn{2}{c}{$\mathrm{R}^{2}$} & \\
\hline Sample & $\mathrm{TD}$ & $\mathrm{RD}$ & $\mathrm{TD}$ & $\mathrm{RD}$ & $\mathrm{TD}$ & $\mathrm{RD}$ \\
Spruce & 0.0009 & 0.0007 & 0.0608 & 0.0718 & 0.9914 & 0.9917 \\
Black pine & 0.0009 & 0.0009 & 0.0725 & 0.0830 & 0.9933 & 0.9831 \\
Chestnut & 0.0009 & 0.0010 & 0.0861 & 0.0983 & 0.9957 & 0.9987 \\
Beech & 0.0010 & 0.0012 & 0.1018 & 0.1162 & 0.9938 & 0.9844 \\
Oak & 0.0011 & 0.0013 & 0.1164 & 0.1308 & 0.9918 & 0.9798 \\
\hline
\end{tabular}

$\mathrm{A}, \mathrm{B}$ - regression coefficients, $\mathrm{TD}$ - tangential direction, $\mathrm{RD}$ - radial direction.

The volume specific heat was calculated as the ratio of thermal conductivity to thermal diffusivity and these values were compared with the experimental results obtained with a thermal parameters analyser Isomet 2104, the difference in values was less than $0.15 \%$. The identified graphical dependencies for the volume specific heat are showed in 
Table 2. Results of regression analyses for the thermal diffusivity relationships

\begin{tabular}{|c|c|c|c|c|c|c|c|c|}
\hline \multirow{2}{*}{$\begin{array}{l}\text { Coefficients of regression } \\
\text { equation (2) } \\
\text { Sample }\end{array}$} & \multicolumn{2}{|c|}{$\begin{array}{c}\mathrm{C} \times 10^{-5} \\
\left(\mathrm{~mm}^{-2} \mathrm{~s}^{-1}\right)(\%)^{-2}\end{array}$} & \multicolumn{2}{|c|}{$\begin{array}{c}\mathrm{D} \times 10^{-4} \\
\left(\mathrm{~mm}^{-2} \mathrm{~s}^{-1}\right)(\%)^{-1}\end{array}$} & \multicolumn{2}{|c|}{$\begin{array}{c}E \\
\left(\mathrm{~mm}^{-2} \mathrm{~s}^{-1}\right)\end{array}$} & \multicolumn{2}{|c|}{$\mathrm{R}^{2}$} \\
\hline & TD & $\mathrm{RD}$ & TD & $\mathrm{RD}$ & TD & $\mathrm{RD}$ & TD & $\mathrm{RD}$ \\
\hline Spruce & 5 & 5 & -4 & -4 & 0.1278 & 0.1302 & 0.9774 & 0.9879 \\
\hline Black pine & 5 & 5 & -5 & -5 & 0.1320 & 0.1346 & 0.9811 & 0.9900 \\
\hline Chestnut & 5 & 5 & -6 & -6 & 0.1385 & 0.1413 & 0.9805 & 0.9800 \\
\hline Beech & 5 & 5 & -2 & -2 & 0.1407 & 0.1434 & 0.9911 & 0.9830 \\
\hline Oak & 5 & 5 & -2 & -2 & 0.1475 & 0.1501 & 0.9945 & 0.9837 \\
\hline
\end{tabular}

C, D, E - regression coefficients. Another explanations as in Table 1.

Table 3. Results of regression analyses for the volume specific heat

\begin{tabular}{|c|c|c|c|c|c|c|c|c|}
\hline \multirow{2}{*}{$\begin{array}{l}\text { Coefficients of regression } \\
\text { equation (3) } \\
\text { Sample }\end{array}$} & \multicolumn{2}{|c|}{$\begin{array}{c}\mathrm{F} \times 10^{-4} \\
\left(\mathrm{~J} \mathrm{~m}^{-3} \mathrm{~K}^{-1}\right)(\%)^{-2}\end{array}$} & \multicolumn{2}{|c|}{$\begin{array}{c}\mathrm{G} \times 10^{-4} \\
\left(\mathrm{~J} \mathrm{~m}^{-3} \mathrm{~K}^{-1}\right)(\%)^{-1}\end{array}$} & \multicolumn{2}{|c|}{$\begin{array}{c}\mathrm{H} \\
\left(\mathrm{J} \mathrm{m}^{-3} \mathrm{~K}^{-1}\right)\end{array}$} & \multicolumn{2}{|c|}{$\mathrm{R}^{2}$} \\
\hline & TD & $\mathrm{RD}$ & TD & $\mathrm{RD}$ & $\mathrm{TD}$ & $\mathrm{RD}$ & $\mathrm{TD}$ & $\mathrm{RD}$ \\
\hline Spruce & -2 & -2 & 67 & 69 & 0.4846 & 0.4991 & 0.9459 & 0.9326 \\
\hline Black pine & -2 & -2 & 80 & 83 & 0.555 & 0.5717 & 0.8458 & 0.8634 \\
\hline Chestnut & -2 & -2 & 82 & 85 & 0.6281 & 0.6469 & 0.8478 & 0.8520 \\
\hline Beech & -2 & -2 & 63 & 65 & 0.7337 & 0.7557 & 0.8581 & 0.8811 \\
\hline Oak & -2 & -2 & 79 & 82 & 0.7920 & 0.8157 & 0.8955 & 0.9037 \\
\hline
\end{tabular}

F, G, H - regression coefficients. Another explanations as in Table 1.

Fig. 4 and the results of a regression analysis are summarized in Table 3 and they can be mathematically expressed using the Eq. (3).

$$
c \rho=F \omega_{r e l}^{2}+G \omega_{r e l}+H .
$$

The value of volume specific heat was the highest for oak at $0.89010^{6} \mathrm{~J} \mathrm{~m}^{-3} \mathrm{~K}^{-1}$ with a radial orientation of the wood fibres and the lowest $c \rho$ was attained by a completely dried sample of spruce with a tangential direction of wood fibres. The results of the volume specific heat calculations for all of the measured samples with a tangential orientation of the wood fibres were in the following ranges: softwood - spruce $\left(0.488-0.53110^{6} \mathrm{~J} \mathrm{~m}^{-3} \mathrm{~K}^{-1}\right)$, black pine (0.565-0.593 $\left.10^{6} \mathrm{~J} \mathrm{~m}^{-3} \mathrm{~K}^{-1}\right)$; hardwood - beech (0.736$\left.0.73510^{6} \mathrm{~J} \mathrm{~m}^{-3} \mathrm{~K}^{-1}\right)$, oak $\left(0.803-0.79010^{6} \mathrm{~J} \mathrm{~m}^{-3} \mathrm{~K}^{-1}\right)$ and medium hardwood - chestnut $\left(0.630-0.65910^{6} \mathrm{~J} \mathrm{~m}^{-3} \mathrm{~K}^{-1}\right)$. The volume specific heat of the wood samples in the radial direction were: softwood - spruce $(0.503-$ $\left.0.57510^{6} \mathrm{~J} \mathrm{~m}^{-3} \mathrm{~K}^{-1}\right)$, black pine $\left(0.582-0.66410^{6} \mathrm{~J} \mathrm{~m}^{-3} \mathrm{~K}^{-1}\right)$, hardwood - beech $\left(0.758-0.82010^{6} \mathrm{~J} \mathrm{~m}^{-3} \mathrm{~K}^{-1}\right)$, oak $(0.813-$ $0.890) 10^{6} \mathrm{~J} \mathrm{~m}^{-3} \mathrm{~K}^{-1}$ ) and medium hardwood - chestnut $\left(0.649-0.72810^{6} \mathrm{~J} \mathrm{~m}^{-3} \mathrm{~K}^{-1}\right)$. In the literature, the values of mass specific heat were presented by Glass and Zelinka, (2010), Peere and Keey (2014), Radmanović et al. (2014) and Igaz et al. (2017), so in order to make a data comparison the values of volume specific heat were divided by the density of the wood sample, the partial results are in good agreement with the values presented in the literature by Czajkowski et al. (2016), Sonderegger et al. (2011), Ružiak et al. (2017) and Kühlmann (1962). They reported that the cause of various values of thermal parameters in the tangential and radial directions of the hardwood samples (oak, beech) is high-density wood fibre, but on the other hand, in the samples of softwood (spruce, pine) it is the low density of wood fibre.

Due to the more complex theoretical interpretation of the results, a correlation analysis was performed, the correlation coefficients for all of the thermal parameters of the wood samples were in the range 0.971-0.999, which indicates a very close correlation.

The last samples to be examined were OSB samples made from the same types of wood waste that originated from wood with a tangential and radial orientation of the wood fibres. A summary of the results of the thermophysical experiments performed are given in Table 4.

Table 4. Results of thermal parameters for samples of OSB boards

\begin{tabular}{lcccccc}
\hline \multirow{2}{*}{ Sample } & \multicolumn{2}{c}{$\begin{array}{c}c \\
\end{array}$} & $\left(\mathrm{~W} \mathrm{~m}^{-1} \mathrm{~K}^{-1}\right)$ & \multicolumn{2}{c}{$\left(\mathrm{mm} \mathrm{s}^{-1}\right)$} & \multicolumn{2}{c}{$c \rho \times 10^{6}$} \\
\cline { 2 - 7 } & $\mathrm{TD}$ & $\mathrm{RD}$ & $\mathrm{TD}$ & $\mathrm{RD}$ & $\mathrm{TD}$ & $\mathrm{RD}$ \\
\hline Spruce & 0.077 & 0.087 & 0.138 & 0.142 & 0.558 & 0.613 \\
Black pine & 0.090 & 0.099 & 0.142 & 0.145 & 0.634 & 0.683 \\
Chestnut & 0.104 & 0.119 & 0.147 & 0.150 & 0.707 & 0.793 \\
Beech & 0.121 & 0.139 & 0.152 & 0.156 & 0.796 & 0.891 \\
Oak & 0.139 & 0.156 & 0.161 & 0.164 & 0.863 & 0.951 \\
\hline
\end{tabular}

$\lambda$ - thermal conductivity, $a$ - thermal diffusivity, $c \rho$ - volume specific heat. Another explanations as in Table 1.

The thermophysical parameters of the measured OSB samples were compared with the values obtained for the wood samples (with a 5\% moisture content) in the radial and tangential direction. In all cases, significant changes in the thermophysical parameters of the OSB samples were identified in comparison with the wood samples (the thermophysical parameters of the wood were considered as a reference). In general, the thermal parameters for the OSB 
samples had a higher value, in comparison, the average percentage differences were calculated for each measured sample and the results are given in Table 5.

Table 5. Differences between the thermal parameters of wood and OSB samples

\begin{tabular}{lccrrrr}
\hline \multirow{2}{*}{ Sample } & \multicolumn{2}{c}{$\begin{array}{c}\Delta \lambda \\
(\%)\end{array}$} & \multicolumn{2}{c}{$\begin{array}{c}\Delta a \\
(\%)\end{array}$} & \multicolumn{2}{c}{$\begin{array}{c}\Delta \rho \\
(\%)\end{array}$} \\
\cline { 2 - 7 } & \multicolumn{1}{c}{ TD } & \multicolumn{1}{c}{ RD } & \multicolumn{1}{c}{ TD } & RD & \multicolumn{1}{c}{ TD } & \multicolumn{1}{c}{ RD } \\
\hline Spruce & 17.56 & 18.46 & 24.43 & 7.81 & 17.21 & 9.84 \\
Black pine & 12.51 & 18.42 & 7.40 & 7.58 & 15.16 & 10.07 \\
Chestnut & 15.54 & 15.55 & 7.14 & 6.91 & 17.66 & 8.10 \\
Beech & 13.93 & 13.08 & 7.58 & 7.04 & 18.01 & 5.71 \\
Oak & 15.55 & 15.83 & 8.69 & 8.05 & 14.58 & 7.20 \\
\hline
\end{tabular}

$\Delta \lambda$ - the difference between the thermal conductivity of wood and OSB samples, $\Delta a$ - the difference between the thermal diffusivity of wood and OSB samples, $\Delta c \rho$ - the difference between the volume specific heat of wood and OSB samples, TD - tangential direction, $\mathrm{RD}$ - radial direction.

The difference between the thermal conductivity values was maximal for the spruce wood sample, in the tangential direction it was $18.46 \%$, in the case of the radial direction a $24.43 \%$ difference was also identified for the thermal diffusivity of the spruce sample. The smallest difference in thermal parameters was attained by OSB made from chestnut wood.

The results show that changes to the material structure (fragment size, arrangement of the component particles, a binder, a curing agent, etc.) had a significant influence on the thermal parameters. An evaluation of the results must take into account the fact that due to the production process of OSB it is difficult to identify the structural characteristics of the original wood waste from which the samples were made and also during their production a binder is added to the basic mixture.

One of the essential factors that can affect the thermophysical parameters of OSB is the mechanical and thermal treatment of the mixture, during the production process the mixture is heated and subsequently pressed, thus creating a compact material - OSB, which has different thermophysical properties from a macroscopic point of view.

\section{CONCLUSIONS}

1. The thermal parameters may be used to create a basic description of thermal transport which cannot be separated from moisture transport.

2. In terms of macroscopic and microscopic structure, the important influence of wood fibre orientation on thermal conductivity was detected. Experiments showed insignificant changes in wood thermal diffusivity for different wood fibre orientation.

3. From a structural point of view the wood samples with a higher fibre density has higher values of thermal parameters.

4. A numerical evaluation of the experimentally obtained results for the oriented strand board samples showed the quantifiable effect of wood type on their thermal parameters.
5. The presented results are beneficial from the point of view of predicting the thermal behaviour of wood and woodbased products during processing, storage and usage.

6 . The study of the influence of internal and external factors is necessary to ensure the quality of wood building structures which are used in the modern construction of wooden houses.

Conflict of interest: The authors declare no conflict of interest.

\section{ACKNOWLEDGEMENTS}

This publication was supported by the Operational Program Integrated Infrastructure within the project: Demand-driven research for the sustainable and inovative food, Drive4SIFood 313011V336, cofinanced by the European Regional Development Fund.

\section{REFERENCES}

Adl-Zarrabi B., 2004. Determination of thermal properties of wood and wood based products by using TPS. Proc. 8th World Conference on Timber Engineering, Lahti, Finland.

Adl-Zarrabi B., Bostrom L., and Wickstrom U., 2006. Using the TPS method for determining the thermal properties of concrete and wood at elevated temperature. Fire Mater., 30, 359-69, https://doi.org/10.1002/fam.915

Avramidis S. and Lau P., 1992. Thermal coefficients of wood particles by transient heat-flow method. Holzforschung, 46, 449-453, https://doi.org/10.1515/hfsg.1992.46.5.449

Beck J.V. and Arnold K.J., 2003. Parameter estimation in engineering and science. John Wiley, New York, USA.

Bouguerra A., Aït-Mokhtar A., Amiri O., and Diop M.B., 2001. Measurement of thermal conductivity, thermal diffusivity and heat capacity of highly porous building materials using transient plane source technique. Int. Commun. Heat Mass Transf., 28, 1065-1078, https://doi.org/10.1016/S07351933(01)00310-4

Czajkowski Ł., Olek W., Weres J., and Guzenda R., 2016. Thermal properties of wood-based panels: specific heat determination. Wood Sci. Technol., 50, 537-545, https://doi. org/10.1007/s00226-016-0803-7

Glass S.V. and Zelinka S.L., 2010. Moisture relations and physical properties of wood. In: Wood handbook : Wood as an engineering material: Chapter 4. Centennial (Eds General technical report FPL). GTR-190, Madison, U.S.

Gustafsson S.E., 1991. Transient plane source techniques for thermal conductivity and thermal diffusivity measurements. Rev. Sei. Instrum., 62, 797-804, https://doi.org/10.1063/1.1142087

Hrčka R. and Kurjatko S., 2006. Thermal properties of elm wood (Ulmus scabra Mill.). In: Wood structure and properties '06. (Eds S. Kurjatko, J. Kudela, R. Lagana). Arbora Publishers, Zvolen, Slovakia.

Igaz R., Krišt’ák L., Ružiak I., Gajtanska M., and Kučerka M., 2017. Thermophysical properties of osb boards versus equilibrium moisture content. BioResources, 12, 8106-8118, https://doi.org/10.15376/biores.12.4.8106-8118 
Karawacki E., Suleiman B.M., Ul-Hang I., and Nhi B.T., 1992. An extension to the dynamic plane source technique for measuring thermal conductivity, thermal diffusivity and specific heat of solids. Rev. Sci. Instrum., 63, 4390-4397, https://doi.org/10.1063/1.1143739

Krišt'ák L', Igaz R. and Ružiak I., 2019. Applying the EDPS Method to the Research into Thermophysical Properties of Solid Wood of Coniferous Trees. Adv Mater Sci Eng, ID2303720, 1-9, https://doi.org/10.1155/2019/2303720.

Kühlmann G., 1962. Investigation of the thermal properties of wood and particleboard in dependency from moisture content and temperature in the hygroscopic range (in German). Holz Roh-Werkst., 20, 259-270, https://doi.org/10.1007/ BF02604682

Li K.Y., Fleischmann C.M., and Spearpoint M.J., 2013. Determining thermal-physical properties of pyrolyzing New Zealand medium density fibreboard (MDF). Chem. Eng. Sci., 95, 211-220, https://doi.org/10.1016/j.ces.2013.03.019

Liang X.G., 1995. The boundary induced error on the measurement of thermal conductivity by transient hot wire method. Meas. Sci. Technol., 6, 467-471, https://doi.org/10.1088/09570233/6/5/005

Malinarič S., 2004. Parameter estimation in dynamic plane source method. Meas. Sci. Technol., 15(4), 807-813, https://doi. org/10.1088/0957-0233/15/5/005

Malinarič S. and Dieška P., 2009. Improvements in the dynamic plane source method. Int. J. Thermophys., 30, 608-618, https://doi.org/10.1007/s10765-008-0525-7

Nakaya T., Yamasaky M., Fukuta S., and Sasaki Y., 2016. Thermal conductivity and volumetric specific heat of lowdensity wooden mats. For. Prod. J., 66, https://doi. org/10.13073/FPJ-D-15-00045

Öner Ü., Ümit B., and Suleyman K., 2009. Properties of wood and wood based materials subjected to thermal treatments under various conditions. Proc. 7th Int. Conf. Wood Science and Engineering in the Third Millenium (ICWSE 2009), Brasov, Romania.

Perre P. and Keey R. B., 2014. Drying of Wood: Principles and Practices. Handbook of Industrial Drying. Taylor \& Francis Group. LLC. Oxfordshire, United Kingdom.

Radmanović K., Đukić I., and Pervan S., 2014. Specific heat capacity of wood. Drvna Industrija, 65, 151-157, https:// doi.org/10.5552/drind.2014.1333
Ružiak I., Igaz R. Krišt’ák L., and Gajtanska M., 2017. Thermotechnic properties of wood-based materials in wood buildings. Technical University in Zvolen, Zvolen, Slovakia.

Sobota T., 2014. Fourier's law of heat conduction. In: encyclopedia of thermal stresses (Ed. R.B. Hetnarski). Springer, Dordrecht, Germany, https://doi.org/10.1007/978-94-007-2739-7_384

Sonderegger W. and Niemz P., 2012. Thermal and moisture flux in soft fiberboards. Eur. J. Wood Prod., 70, 25-35, https:// doi.org/10.1007/s00107-010-0498-7

Sonderegger W., Hering S., and Niemz P., 2011. Thermal behaviour of Norway spruce and European beechin and between the principal anatomical directions. Holzforschung, 65, 369-375, https://doi.org/10.1515/hf.2011.036

Suleiman B., Larfeldt J., and Leckner B., 1999. Thermal conductivity and diffusivity of wood. Wood Sci. Technol., 336, 465-473, https://doi.org/10.1007/s002260050130

Tavman I.H., 1996. Effective thermal conductivity of granular porous materials. Int. Commun. Heat Mass Transf., 23(2), 169-176, https://doi.org/10.1016/0735-1933(96)00003-6

Troppova E., Svehlık M., Tippner J., and Wimmer R., 2014. Influence of temperature and moisture content on the thermal conductivity of wood-based fibreboards. Mat. Struct., 48, https://doi.org/10.1617/s11527-014-0467-4

Wakeham W.A., Nagashima A., and Sengers V.J., 1991. Experimental thermodynamics. Blackwell Scientific Publications, London, UK.

Wechsler A.E., 1992. The probe method for measurement of thermal conductivity in compendium of thermophysical property measurement methods. Recommended measurement techniques and practices, Plenum Press, New York, London, USA, UK, https://doi.org/10.1007/978-1-4615-3286-6_6

Zhou J., Zhou H., Hu Ch., and Hu S., 2013. Measurement ofthermal and dielectric properties of medium density fiberboard with different moisture contents. BioResources, 8, 4185-4192, https://doi.org/10.15376/biores.8.3.4185-4192

Zi-Tao Y., Zi-Tao Y., Xu X., Li-Wu F., Ya-Cai H. and Ke-Fa, C., 2011. Experimental measurements of thermal conductivity of wood species in China: effects of density, temperature, and moisture content. For. Prod. J., 61, 130135, https://doi.org/10.13073/0015-7473-61.2.130 